\title{
Large differences in variability for genes associated with antimalarial drug resistance between samples from Tanzania and Ethiopia
}

\author{
Lemu Golassa', Nizar Enweji ${ }^{1}$, Göte Swedberg ${ }^{1 *}$, Erasmus Kamugisha ${ }^{2}$, Angel Choy ${ }^{1}$ \\ From Challanges in malaria research: Core science and innovation \\ Oxford, UK. 22-24 September 2014
}

\section{Background}

Changes in antimalarial drug policy lead to selection of the most successful parasite clones. In spite of a change to Artemisinin Combination Therapy (ACT), we have earlier shown a low degree of variability for the chloroquine resistance marker pfcrt in samples of Plasmodium falciparum from Ethiopia with $100 \%$ carrying the crucial K76T variant [1].

\section{Materials and methods}

The study material was collected in the Shalla district, Oromia, Ethiopia, and in different parts of Tanzania. Genetic polymorphisms in the genes $p f m d r 1$ and $p f u b p 1$ were analysed by PCR and nucleotide sequence determinations.

\section{Results}

A surprising finding was that a majority of Ethiopian isolates carried the wild type variant of $p f m d r 1$. The majority of samples from different regions of Tanzania were wild type for both $p f c r t$ and $p f m d r 1$. Analysis of a variable linker region in $p f m d r 1$ showed substantial variation in samples from Tanzania, but minimal variation in samples from Ethiopia. The variable part consists of consecutive NDN residues. The dominating variant in Ethiopians was $7 / 2 / 9$ and $7 / 2 / 10$ in Tanzania. The same pattern was seen for a variable part of the $p f u b p 1$ gene, where all Ethiopian samples were identical to 3D7. In 19 Tanzanian samples only 8 were identical to 3D7 with 5 other variants. A polymorphism at codon 1528, detected previously in Kenyan samples [2] was found in 2 Tanzanian samples.

\section{Conclusions}

While the presence of the mutant variant of $p f c r t$ in the Ethiopian samples can be explained by continued use of chloroquine in Ethiopia for treatment of $P$. vivax, the selection of wild type $p f m d r 1$ could be a consequence of using ACT for treatment of $P$. falciparum. In general, the variability in both studied genes was greater in Tanzania than in Ethiopia. There are no data yet to link the variability in pfubp1 to efficacy of ACT.

\section{Authors' details \\ 'Uppsala University, Uppsala, Sweden. ${ }^{2}$ Catholic University of Health and Allied Sciences, Mwanza, Tanzania.}

Published: 22 September 2014

\section{References}

1. Golassa L, Enweji N, Erko B, Aseffa A, Swedberg G: High prevalence of pfcrt-CVIET haplotype in isolates from asymptomatic and symptomatic patients in south-central Oromia, Ethiopia. Malaria J 2014, 13:120.

2. Borrmann S, et al: Genome-wide screen identifies new candidate genes associated with artemisinin susceptibility in Plasmodium falciparum in Kenya. Sci Rep 2013, 3:3318.

doi:10.1186/1475-2875-13-S1-P87

Cite this article as: Golassa et al.: Large differences in variability for genes associated with antimalarial drug resistance between samples from Tanzania and Ethiopia. Malaria Journal 2014 13(Suppl 1):P87.

${ }^{1}$ Uppsala University, Uppsala, Sweden

Full list of author information is available at the end of the article 